The anaesthetists reported that they were often called too late to be able to assess the patient adequately.

It takes experience to husband obstetric and anaesthetic resources efficiently. If there is not enough participation at consultant level then neither the midwives, obstetricians, nor junior anaesthetists will receive guidance on making the best use of available resources or in anticipating crises. The social services committee report recommends "that a 24 hour service for epidural anaesthesia should be available as an important priority in consultant obstetric units." In the mid-1980s epidural analgesia can no longer be considered a luxury but a medical service that should be available to obstetric patients.

In one unit with roughly 2000 deliveries annually the midwives said they "never had a patient who would benefit from an epidural." This is a disturbing statement reflecting not only the lack of education of the midwives but also the lack of consultant anaesthetic notional half days and the isolation of the unit (see table I and II). While isolated units continue to exist throughout Britain epidural analgesia will never be readily available nationally since an anaesthetist should always be available wherever mothers receive epidurals so that he can attend within five minutes of any complication. The quality of the epidural service probably reflects not only the availability of first class obstetric general anaesthesia but also obstetric care. To quote from the third report from the Social Services Committee, ${ }^{3}$ the main recommendation in the anaesthetic section is: "We recommend that the DHSS and the profession examine ways of ensuring provision of a safe obstetric anaesthetic service throughout the country."
We think that it is the responsibility of the profession to examine anaesthetic on call arrangements for every consultant obstetric unit and to ascertain whether better arrangements can be made within available resources. It would appear to be the duty of the district and regional general managers, acting on the advice of the medical staff, to ensure the speedy centralisation of isolated obstetric units and the provision of adequate consultant anaesthetic notional half days.

Finally, a quotation from Karl Kraus (Aphorisms and More Aphorisms, 1909) would be appropriate: "Women's rights are men's duties." It is surely the right of every obstetric patient to expect a first class anaesthetic service should she require it.

We thank all the anaesthetists, midwives, and obstetricians who helped with this survey, which was supported by a grant from the Obstetric Anaesthetists Association. Mrs J Arundale has kindly typed the manuscript, and copies of the whole survey may be obtained from Dr Macdonald.

\section{References \\ 1 Department of Health and Social Security. 26th Report on confidential enquiries into maternal deaths in England and W'ales. 1976-1978. London: HMSO, 1982. \\ Social Services Committee. The second report from the Social Sericices Committee session 1979-80. Perinatal and Neonatal Mortality. I. London: HMSO, 1980. \\ 3 Social Services Committee. The third report from the Social Seritces Committee session 1983-84. Pernatal and Neonatal Mortality report: follow-up. London: HMSO, 1984. \\ Accepted 13 May 1986)}

\title{
Treatment of high blood pressure: should clinical practice be based on results of clinical trials?
}

\author{
R G WILCOX, J R A MITCHELL, J R HAMPTON
}

There is no longer any debate about the association between the height of the systemic arterial pressure and the subsequent risk of death or disability. ${ }^{\prime}$ In the past the prognosis of patients with untreated malignant or accelerated phase hypertension was appalling but the benefits of treatment were easy to show and such patients were obliged to submit to surgical sympathectomy, rigorous diets, and, later, the side effects of pharmacological sympathectomy. The benefits of treatment have been less easy to show in patients with non-accelerated hypertension. Since the pioneering trials of the Veterans Administration time has complicated the issue. Firstly, diastolic blood pressure has been used as the reference point for treatment in most trials, but nowadays more attention is being paid to systolic blood pressure. ${ }^{2}$ Secondly, by the time some trials have ended the drug regimen tested has been superseded by newer products. Thirdly, as the hypertensive

Department of Medicine, University Hospital, Queen's Medical Centre, Nottingham NG7 2UH

R G WILCOX, DM, MRCP, senior lecturer in medicine

J R A MITCHELL, MD, FRCP, professor of medicine

J R HAMPTON, DM, FRCP, professor of cardiology population comprises different sex, age, and ethnic groups we need to know which subgroups are likely to benefit (or perhaps even be harmed) by drug intervention. Fourthly, debate continues about the potential hidden risks of long term drug treatment. ${ }^{+5}$ Finally, interest in non-pharmacological remedies is growing. ${ }^{67}$

Some doctors continue to rely on personal experience while others are influenced by the known association between high blood pressure and cardiovascular disease. Personal experience and associations established from epidemiological data should form the basis for clinical trials, not for clinical practice. In this review we analyse the effect of treatment on survival and cardiovascular events as shown by the major controlled trials and try to derive from these results a practical policy for treating patients with high blood pressure.

\section{The trials}

Nine trials of the effect of reducing blood pressure have now been completed, in which more than 50000 patients participated (table I). At the simplest level, we should be able to assume that a trial has asked the right questions, included the right patients, and tested the right treatment. Surprisingly, several of the trials fail by even such simple criteria. If we are to 
accept a trial as a basis for clinical practice the patients included should have been randomly allocated to active or placebo treatment, enough should have been studied to give a reasonable chance of a clear answer, and the trial should have been conducted and analysed according to currently accepted standards. Unfortunately, some of the trials are inadequate by these criteria.

TABLE I-Type of patient, blood pressure, and number of patients included in major trials of reduction of blood pressure

\begin{tabular}{|c|c|c|c|}
\hline Trial & Patients & $\begin{array}{l}\text { Blood pressure } \\
(\mathbf{m m ~ H g})\end{array}$ & $\begin{array}{c}\text { No of } \\
\text { patients }\end{array}$ \\
\hline $\begin{array}{l}\text { Veterans Administration }{ }^{89} \\
\text { Gothenburg }{ }^{10}\end{array}$ & $\begin{array}{l}\text { Men in hospital } \\
\text { Men aged 47-54 }\end{array}$ & $\begin{array}{l}\text { Diastolic }>90 \\
\text { Systolic }>175 \text { or } \\
\text { diastolic }>115\end{array}$ & $\begin{array}{l}523 \\
635\end{array}$ \\
\hline $\begin{array}{l}\text { Hypertension detection and } \\
\text { follow up programme }{ }^{1112} \\
\text { Oslo }^{13} \\
\text { Australian } \\
\text { Multiple risk factor } \\
\text { Multiple }\end{array}$ & $\begin{array}{l}\text { Men and women aged 30-69 } \\
\text { Men aged 40-49 } \\
\text { Men and women aged 30-69 }\end{array}$ & $\begin{array}{l}\text { Diastolic }>90 \\
150-179 />100 \\
\text { Diastolic } 95-109\end{array}$ & $\begin{array}{r}10940 \\
785 \\
3427\end{array}$ \\
\hline $\begin{array}{l}\text { interventions trial } \\
\text { European } \\
\text { International prospective }\end{array}$ & $\begin{array}{l}\text { "High risk" men aged } 35.59 \\
\text { Men and women over } 60\end{array}$ & $\begin{array}{l}\text { Diastolic } 90-115 \\
\text { Diastolic } 90-119\end{array}$ & $\begin{array}{r}12866 \\
940\end{array}$ \\
\hline $\begin{array}{l}\text { primary prevention study }{ }^{18} \\
\text { MRC }^{19}\end{array}$ & $\begin{array}{l}\text { Men and women aged 40-69 } \\
\text { Men and women aged 35-60 }\end{array}$ & $\begin{array}{l}\text { Diastolic 100-125 } \\
\text { Diastolic } 90-109\end{array}$ & $\begin{array}{r}6357 \\
17354\end{array}$ \\
\hline Total & & & 53827 \\
\hline
\end{tabular}

\section{DID THE TRIALS ASK THE RIGHT QUESTION?}

The hypertension detection and follow up programme (HDFP) was not a trial of blood pressure reduction but was a randomised comparison of two forms of management: by specialised centres (special care) or by the patient's usual practitioner (referred care). "In the multiple risk factor intervention trial (MRFIT) the aim was to compare in high risk patients the outcome of correction of all major risk factors (high blood pressure, high cholesterol concentrations, smoking) by special intervention clinics with that in patients assigned to routine care. ${ }^{16}$ The Gothenburg primary prevention study (GPPS) was also designed to assess whether multiple interventions can prevent coronary disease when $\beta$ blockers are given as the drug of first choice..$^{10}$ The international prospective primary prevention study in hypertension (IPPPSH) was not a hypertension trial at all but specifically asked whether the inclusion of a $\beta$ blocker (oxprenolol) in a treatment regimen conferred any particular benefit. ${ }^{18}$

\section{WERE THE RIGHT PATIENTS INCLUDED?}

The Veterans Administration studies included a most atypical collection of men, of whom $54 \%$ were Negroes in the first trial and $40 \%$ in the second. ${ }^{89}$ They had a high prevalence of cardiovascular disease and over the run in period to the trial showed their willingness to comply with treatment.

Until the study of the European working party on hypertension in the elderly (EWPHE) was reported ${ }^{17}$ most hypertension trials had either included very few elderly patients or specifically excluded them. In the European study the entry age was 60 but the age range and the age stratification between treatment and control groups are not stated. A low inclusion rate for each centre suggests that some undisclosed selection criteria may have been used inadvertently.

Both the Australian national blood pressure study (ANBPS) and the Medical Research Council (MRC) trial included men and women who were considered to be free from cardiovascular or other serious disease at entry, although they differed in their age ranges (30-69 and 35-64 respectively) and ranges of diastolic blood pressure $(90-114 \mathrm{~mm} \mathrm{Hg}$ and $90-109 \mathrm{~mm} \mathrm{Hg}$ respectively)..$^{1+14}$

\section{WAS THE RIGHT TREATMENT TESTED?}

Table II shows the treatment regimens used in the different trials. Any trial entailing long periods of recruitment and follow up will necessarily answer a question about "old fashioned treatment." Furthermore, treatment schedules may be dominated by national licensing laws, long term experience, or even pharmaceutical interests such that comparison between trials in different countries is made more difficult. The early Veterans Administration studies, for instance, used a step care regimen (hydrochlorothiazide, reserpine, hydralazine), which has never been common in Europe and is now much less often used in the United States.
The almost ubiquitous use of diuretics as first line or background treatment in many trials has become the scapegoat for the unexpectedly poor results of some of them (the multiple risk factor intervention trial and the Oslo study). The MRC study probably laid the diuretic ghost, for in the study bendrofluazide was prescribed as a randomised first line drug even though it was used at two or three times its usual hypotensive dose. Even the relatively modern treatments used in the MRC trial (bendrofluazide $v$ propranolol $v$ placebo) could be supplemented by much older drugs (guanethidine and methyldopa). In the Australian study chlorothiazide was compared with placebo, and thereafter the second and third order drugs for the group given active treatment offered a wide choice (methyldopa, propranolol or pindolol, and hydralazine or clonidine, respectively).

If the chosen drug is important for its other pharmacological properties rather than just its ability to lower blood pressure then analyses based on such polyglot schedules may not be reliable. The results of a particular trial cannot with confidence be extrapolated to treatment with other agents, such as cardioselective $\beta$ blockers, calcium antagonists, or angiotensin converting enzyme inhibitors.

WERE THE TRIALS RANDOMISED, DOUBLE BLIND, PLACEBO CONTROLLED, AND LARGE ENOUGH?

Unless it is proved that intervention confers a significant advantage over inaction we believe that a prospective placebo controlled randomised trial is mandatory. In the Gothenburg primary prevention study the patients were not randomly assigned to active or placebo treatment, but the control group comprised men who lacked the criteria considered to necessitate treatment. Of the other hypertension trials, only the Veterans Administration, Australian, European, and international prospective primary prevention studies were double blind (table II); the MRC study was single blind, and the other were open.

Although some of the studies contained large numbers of patients (table I), the size of the Veterans Administration, Oslo, Gothenburg, and European studies does not seem to have been calculated in advance or the rules for stopping defined, so the results must be interpreted with caution.

\section{WAS THE TRIAL PROPERLY CONDUCTED AND ANALYSED?}

If the results are inspected frequently while a trial is in progress there is a danger that a significant difference between treatment groups will be detected because the difference between the groups is bound to fluctuate

TABLE II-Treatment regimen and trial design in hypertension studies

\begin{tabular}{|c|c|c|c|c|c|}
\hline Trial & $\begin{array}{c}\text { Ran- } \\
\text { domised }\end{array}$ & $\begin{array}{l}\text { Double } \\
\text { blind }\end{array}$ & $\begin{array}{l}\text { Single } \\
\text { blind }\end{array}$ & Placebo & Active treatment \\
\hline $\begin{array}{l}\text { Veterans } \\
\quad \text { Administration }\end{array}$ & + & + & & + & $\begin{array}{l}1 \text { Hydrochlorothiazide + reserpine } \\
+ \text { hydralazine }\end{array}$ \\
\hline Gothenburg & & & & & $\begin{array}{l}\text { *1 } \text { Plocker } \\
2 \text { Thiazide diuretic } \\
3 \text { Hydralazine } \\
4 \text { Spironolactone or bethanidine or } \\
\text { high dose frusemide }\end{array}$ \\
\hline $\begin{array}{l}\text { Hypertension } \\
\text { detection and } \\
\text { follow up } \\
\text { programme }\end{array}$ & + & & & & $\begin{array}{l}\text { *1 Chlorthalidone or triamterene or } \\
\text { spironolactone } \\
2 \text { Reserpine or methyldopa } \\
3 \text { Hydralazine } \\
4 \text { Guanethidine } \pm 2 \text { or } 3 \\
5 \text { Others }\end{array}$ \\
\hline Oslo & + & & & & $\begin{aligned} * 1 & \text { Hydrochlorothiazide } \\
2 & \text { Methyldopa or propranolol } \\
3 & \text { Others }\end{aligned}$ \\
\hline Australian & + & & + & + & $\begin{array}{l}\text { *1 Chlorothiazide } \\
2 \text { Methyldopa or propranolol or } \\
\text { pindolol } \\
3 \text { Hydralazine or clonidine }\end{array}$ \\
\hline $\begin{array}{l}\text { Multiple risk } \\
\text { factor interven- } \\
\text { tions trial }\end{array}$ & + & & & & $\begin{array}{l}\text { *1 Hydrochlorothiazide or } \\
\text { chlorthalidone } \\
2 \text { Reserpine or hydralazine or } \\
\text { guanethidine or others }\end{array}$ \\
\hline European & + & + & & + & $\begin{aligned}{ }^{*} 1 \text { Hydrochlorothiazide or triamterene } \\
2 \text { Methyldopa }\end{aligned}$ \\
\hline $\begin{array}{l}\text { International } \\
\text { prospective } \\
\text { primary } \\
\text { prevention } \\
\text { study }\end{array}$ & + & + & & + & $\begin{array}{l}{ }^{* 1} \text { Slow release oxprenolol } \\
2 \text { Other non- } \beta \text {; blockers }\end{array}$ \\
\hline $\mathrm{MRC}$ & + & & + & + & $\begin{array}{l}{ }^{\star} 1 \text { Bendrofluazide or propranolol } \\
2 \text { Methyldopa }\end{array}$ \\
\hline
\end{tabular}

* Step care treatment. 
with time: as the number of patients in the trial increases the fluctuation lessens. The results of a trial conducted on a basis of "multiple looks" are therefore less certain than those of trials based on a fixed duration or fixed number of patients, and if several looks are to be used a much higher degree of significance is needed for a difference between groups to be considered meaningful. Several looks would seem to have been one of the major disadvantages of the Veterans Administration study. This study seems to have been set up as a single trial and was divided into two subsets (of patients with diastolic pressures of $90-114 \mathrm{~mm} \mathrm{Hg}$ and $115-129 \mathrm{~mm} \mathrm{Hg}$ ) post hoc, on a several looks basis. It may be more accurate to combine the two subgroups to analyse the results.

The proper analysis of a trial is on the basis of "intention to treat," with the patients retained for purposes of analysis in the treatment groups to which they were originally assigned whether or not they were later withdrawn. ${ }^{20}$ It is essential that all patients withdrawn from treatment should be followed up for the full duration of the trial, for failure to know the outcome in such patients could bias the analysis. In the Veterans Administration study the outcome in such patients is unknown, so analysis on the basis of intention to treat is not possible.

\section{Results of the trials}

\section{MORTALITY}

The figure shows the $95 \%$ confidence intervals of the differences in mortality observed between the groups of patients in the "active" and "control" groups of the various trials. For example, in the Veterans Administration trial the overall result (all patients, diastolic pressure 90-129 $\mathrm{mm} \mathrm{Hg}$ ) showed active treatment to be associated with a $60 \%$ reduction in mortality (mortality was $9.5 \%$ in the placebo group compared with $3.8 \%$ in the patients given active treatment). We can be $95 \%$ certain that the "true" result in these groups of patients lies between a $21 \%$ and a $100 \%$ decrease in mortality. The figure shows that in only two trials (the Veterans Administration and the hypertension detection and follow up programme) were the $95 \%$ confidence intervals clear of the line of zero effect-in other words, the observed reduction in mortality was significant. Later trials tended to have narrower confidence intervals, but the observed differences in outcome between patients given active or control treatment were much smaller.

The Veterans Administration trial was among the first to subject patients with non-accelerated hypertension to a prospective placebo controlled randomised study. Although the study population was quite atypical, the trial is unusual in being almost devoid of any formal statistical analysis. In the subgroup with diastolic pressures of $90-114 \mathrm{~mm} \mathrm{Hg} 21(8 \cdot 4 \%)$ of the 194 patients in the control group and $10(5 \cdot 4 \%)$ of the 186 patients in the treated group died (NS). In the subgroup with diastolic pressures of $115-129 \mathrm{~mm} \mathrm{Hg}$ $4(5 \cdot 7 \%)$ of the 70 patients in the control group and none of the 73 in the treated group died (NS). Because of missing data, analysis on the basis of intention to treat is impossible; combining the trials, however, shows the difference in fatal events, by on treatment analysis, to be significant $(\mathrm{p}<0.025)$. The major claims of these two reports considered separately thus resided in the differences in non-fatal complications-namely, cardiac failure, progressive retinopathy, deterioration in renal function, and stroke.

The Australian national study was stopped by the management committee

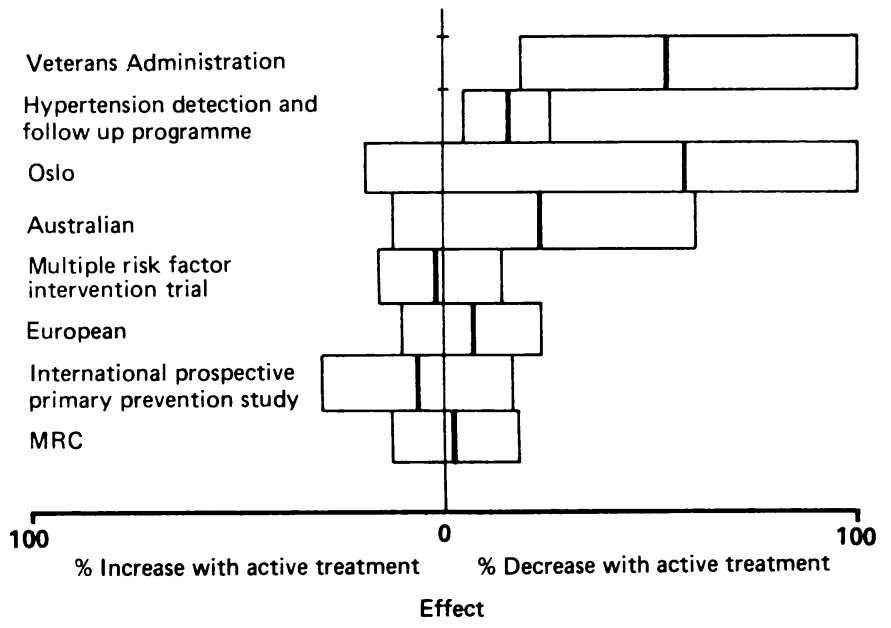

Hypertension trials: $95 \%$ confidence intervals for differences in mortality. Bold vertical bars indicate mean reduction (or increase). after a single examination of the results showed a trend in total trial end points that was differentiating the two groups. Total deaths, however, were $35(2.0 \%)$ of the 1706 patients in the control group and $25(1.4 \%)$ of the 1721 patients in the treated group (NS). Of these deaths, 13 and eight, respectively, were cardiovascular deaths, giving rates per 1000 person years of 2.6 and $1 \cdot 1(p<0.025)$. The total number of trial end points (death, nonfatal cerebral or myocardial events, congestive cardiac failure, dissecting aneurysm of the aorta, retinopathy, hypertensive encephalopathy, renal failure) was $168(9.8 \%)$ in the 1706 controls and $138(8.0 \%)$ in the 1721 in the treated group (rates of 24.5 and $19 \cdot 7 / 1000$ person years, $p<0.05$ ).

In the European study only one table on an intention to treat basis was published; this showed that 149 of the 424 patients $(35 \cdot 1 \%)$ in the placebo group and 135 of the $416(32.4 \%)$ in the treated group died (NS). In the MRC study, by far the largest with over 85000 patient years of observation, 253 of the 4525 controls and 248 of the 4523 patients in the treated groups died, giving rates of 5.9 and $5.8 / 1000$ patient years respectively (NS). There were no differences between the groups in cardiovascular and non-cardiovascular deaths, the proportion of cardiovascular deaths being $139 / 253(54.9 \%)$ in the placebo group and $134 / 248(54 \cdot 0 \%)$ in the treated group.

Of the other trials, the hypertension detection and follow up programme reported a $17 \%$ difference in five year total mortality between the groups given referred and special care $(7 \cdot 7 v 6 \cdot 4 / 100, \mathrm{p}<0.01)$. Non-cardiovascular mortality was also reduced in the special care group, by $14 \%$, and in some blood pressure subgroups the benefit in mortality from non-cardiovascular causes considerably exceeded that from cardiovascular causes, implying that better medical care had an important bearing on the outcome.

\section{STROKE}

The Veterans Administration studies dealt with a highly selected population. In the patients with diastolic pressures of $115-129 \mathrm{~mm} \mathrm{Hg}$ no fatal strokes and only five non-fatal strokes occurred (four in the placebo and one in the active treatment group). In the patients with diastolic pressures of 90-114 mm Hg, however, strokes were, surprisingly, more common: seven fatal strokes and two non-fatal strokes occurred in the placebo group and one fatal and no non-fatal strokes occurred in the active treatment group. These numbers are, of course, far too small to achieve significance.

In the hypertension detection and follow up programme an impressive difference in the incidence of stroke was observed, for 52 of the 5455 patients allocated to routine care died of strokes compared with 29 of the 5485 patients who received special care. ${ }^{12}$ Non-fatal strokes similarly showed a considerable difference (106 $v 73$ ). In contrast to the Australian and MRC studies, this programme also found an equally striking reduction in fatal strokes in the subgroup with mild to moderate hypertension (90-104 mm diastolic): $17(7 \cdot 4 \%)$ of the 231 deaths among patients given special care who died were due to stroke, compared with $31(10 \cdot 7 \%)$ of the 291 deaths among patients given routine care. No tests of significance were given because the trial "precluded assurances of unbiased ascertainment of cause of death."

The Australian national study dealt with a group from which patients in whom there was suspicion of target organ damage had been removed, so the incidence of events was low. Analysis of all the patients in their original, intention to treat groups showed six fatal strokes, 16 non-fatal strokes, and nine transient ischaemic attacks in the placebo group compared with only three, 10 , and four, respectively, in the patients given active treatment $(p<$ 0.05 for all cerebrovascular events and $p<0.05$ for all non-fatal events).

Until the report of the European study was published the only study to compare outcome in elderly subjects randomly allocated to receive treatment or to be observed was one mounted in Nottingham in patients whose mean age was $82 .{ }^{21}$ This study found that treatment conferred no benefit; moreover, lower pressures were associated with reduced survival. The results of the European trial are therefore important but leave many questions unanswered. The age composition of the patients is not adequately described, and, considering that the whole of Europe was meant to contribute elderly hypertensive patients to the study, the number who remained in the trial to the end was extremely small. The presentation of the results lacks the clarity of the Australian study, but if the same measures of stroke outcome are used as in the Australian trial there were 31 fatal events, 17 non-fatal strokes, and 15 transient ischaemic attacks in the placebo group compared with 21,11 , and eight, respectively, in the active treatment group. Unlike most of the other studies, the European one claimed that it had significantly reduced cardiac events but accepted that cerebrovascular mortality was not reduced. Nonfatal strokes in the European study are hard to analyse because they were subdivided into "terminating" and "nonterminating" types.

In the MRC trial the group assigned to receive placebo eventually sustained 27 fatal and 82 non-fatal strokes, whereas the active treatment group sustained 18 fatal and 42 non-fatal events (difference in total strokes between the groups $p<0.01$ ). Bendrofluazide seemed to prevent strokes slightly more effectively than $\beta$ blockers. 
The Australian and MRC trials were large enough to allow the effort required to prevent a stroke to be estimated. In the Australian trial treatment of 1721 patients prevented 14 strokes, so 1707 patients were treated "unnecessarily." In the MRC trial 850 patients had to be treated for a year to prevent one stroke and the monetary cost of preventing a stroke with bendrofluazide was $£ 2100$, compared with $£ 33083$ when propranolol was used.

\section{CARDIAC MORBIDITY AND MORTALITY}

In the combined Veterans Administration trials ( $523 \mathrm{men}$ ) three fatal and four non-fatal myocardial infarcts occurred in the control groups compared with two fatal and five non-fatal infarcts in the actively treated groups. In addition, nine sudden deaths occurred (cause not specified) and 13 patients developed severe congestive cardiac failure in the control groups compared with four sudden deaths but no congestive cardiac failure in the treatment groups. On the assumption that the sudden deaths were due to ischaemic heart disease the total number of cardiac events was 29 in the control group and 11 in the treated group.

In the Australian trial $72 \%$ of all the terminating end points were due to ischaemic heart disease. Eleven fatal and 22 non-fatal infarcts occurred in the control group compared with five and 28 , respectively, in the active group. In addition, 76 other non-fatal cardiac terminating events occurred in the control group and 65 in the treated group. Although overall these figures represent $10 \%$ fewer cardiac events in the treated group (109 $v 98$ ), the differences are not significant.

The European study produced a different result. Of the 149 deaths in the placebo group, 31 were attributed to cerebrovascular causes, 47 to cardiac causes, and 15 to other cardiovascular problems; among the 135 deaths in the active group the comparable figures were 21,29 , and 17 , respectively. In other words, the claims made by all other trials (reduction in stroke but no reduction in heart disease) were reversed. The difference in cardiac mortality was significant, although that in overall mortality was not. It is not possible to comment on non-fatal events by intention to treat analysis in the European study.

The results of the MRC study seem to conform with the general pattern of stroke as against coronary benefit. Of the 253 deaths in the placebo group, 97 $(38 \%)$ were attributed to myocardial infarction, compared with 108 of the 248 deaths $(43 \%)$ in the active group (NS). There were 137 non-fatal infarcts in the placebo group and 116 in the group given active treatment, giving rates of $3 \cdot 2$ and $2 \cdot 7 / 1000$ patient years respectively (NS). The overall rate of coronary events was thus not significantly affected by treatment $(5.5$ in the placebo group and $5 \cdot 2$ in the active group). There was, however, a significant reduction in all cardiovascular events (352 in the placebo group $(8 \cdot 2 / 1000$ patient years) $v 286$ in the active group $(6 \cdot 7 / 1000) ; \mathrm{p}<0.01)$. Again, in contradistinction to the hypertension detection and follow up programme there was no difference in non-cardiovascular death (both rates $2 \cdot 7 / 1000$ patient years).

None of the other studies showed a benefit from active treatment with regard to coronary events. The hypertension detection and follow up programme reported $26 \%$ fewer deaths attributable to acute myocardial infarction in the special care group compared with the routine care group ( 51 $v 69$ ). In that study, however, there was no difference in the proportion of deaths attributable to a combination of infarction, other ischaemic heart disease, and hypertensive heart disease $(136 / 349(39 \%)$ of all deaths in the special care group compared with $155 / 419(37 \%)$ in the referred care group).

The results of the international prospective primary prevention study and the Australian and MRC studies showed that treatment with a thiazide had a broadly similar effect to treatment with a $\beta$ blocker. The international study specifically addressed the question raised by the Gothenburg study of whether the inclusion of a $\beta$ blocker (oxprenolol) in the antihypertensive regimen conferred any benefit. From over 25000 patient years at risk it reported similar relative rates for sudden death, myocardial infarction, and stroke in groups given and not given the $\beta$ blocker.

\section{RESULTS OBTAINED FROM ANALYSIS OF PATIENT SUBGROUPS}

At the end of a large study investigators are sometimes tempted to look for subgroups of their patients who responded particularly favourably to treatment. Results obtained in this way must be interpreted cautiously because in such an examination apparently significant results are bound to occur by chance. Ideally, such findings should form the basis of further trials rather than dictate treatment in specific circumstances. With these reservations it is fair to ask whether any patterns have emerged from the various subgroup analyses so far reported.

Perhaps the most important result obtained by analysing subsets of patients constructed after the end of the trials is that smoking is a more important risk factor than a modest increase in blood pressure. In the MRC trial there was a greater difference in the incidence of strokes and all cardiovascular events between smokers and non-smokers than between the groups given active and placebo treatment. In addition, subset analysis suggested that smoking modified the response to treatment: in both the international prospective primary prevention study and the MRC trial a $\beta$ blocker (oxprenolol and propranolol, respectively) seemed to benefit nonsmokers but not smokers. In the MRC trial bendrofluazide reduced the incidence of strokes in both.

The various trials do not show any consistent relation between the height of the systolic and diastolic blood pressure and the subsequent incidence of stroke and coronary events. Although in the international prospective primary prevention study the incidence of events seemed to increase only above diastolic pressures of about $100 \mathrm{~mm} \mathrm{Hg}$, there is no clear evidence that the higher the pressure treated the greater the benefit to be gained. The deficiencies of the Veterans Administration report of patients with initial diastolic pressures of $115-129 \mathrm{~mm} \mathrm{Hg}$ have been discussed above; although in the European study treatment led to a greater reduction in end points in patients with initial diastolic pressures of $100-119 \mathrm{~mm} \mathrm{Hg}$ than in patients with initial pressures of $90-99 \mathrm{~mm} \mathrm{Hg}$, the hypertension detection and follow up programme produced contrary evidence, for in this it was the patients with the lower pressures who benefited most from special care. The results obtained in patients with different pressures in the MRC trial have yet to be published.

In the hypertension detection and follow up programme there was no significant difference between special care and referred care in overall mortality in any sex or racial group aged below 50 . Above this age the death rates over five years were lower by $15-28 \%$ in the special care group except in white women. Non-fatal strokes were not reduced in black men. No age effect was found in the Australian study; in this study the effects of treatment were reduced in patients with a higher serum cholesterol concentration, but this was not confirmed in the multiple risk factor intervention trial. The Australian study showed an increasing benefit from treatment with decreasing body weight (especially in smokers and in women), but in the international prospective primary prevention study no separate effect of body weight was detected.

This lack of consistency of results obtained by subset analysis shows that none of the individual findings can safely be used as a basis for clinical practice.

\section{DISADVANTAGES OF TREATING HIGH BLOOD PRESSURE}

Some of the hypertension trials have shown that raised blood pressure often becomes normal with placebo treatment. In the Australian study $47 \%$ of the patients given placebo achieved a diastolic pressure of less than $95 \mathrm{~mm} \mathrm{Hg}$ within three years, most within the first four months. In the MRC, study, too, roughly $40 \%$ of the men and $45 \%$ of the women in the placebo group had a diastolic pressure of less than $90 \mathrm{~mm} \mathrm{Hg}$ after one year. The modest benefits of active treatment shown in the MRC trial were bought at a considerable logistical price $(695000$ invitations to attend for screening were sent out, 515000 subjects screened, and 17354 subjects entered into a five year study). A price was also paid in respect of drug side effects, and the prevention of strokes in a few patients entailed long term side effects ("mostly, but not all, minor") in many patients, such as gout, impotence, lethargy, and Raynaud's phenomenon.

\section{SUMMARY OF RESULTS}

Table III summarises the main results of the trials, though we believe that many of these apparently positive results should be interpreted with caution.

TABLE III-Summary of principal results of trials. Parentheses indicate that results should be interpreted with caution

\begin{tabular}{|c|c|c|c|c|c|}
\hline \multirow[b]{2}{*}{ Trial } & \multirow{2}{*}{$\begin{array}{c}\text { Total } \\
\text { mortality }\end{array}$} & \multicolumn{2}{|c|}{ Heart attack } & \multicolumn{2}{|c|}{ Stroke } \\
\hline & & Fatal & Total & Fatal & Total \\
\hline Veterans Administration (combined) & $(+)$ & & & & $(+)$ \\
\hline Gothenburg & $(+)$ & & $(+)$ & & \\
\hline Hypertension detection and follow up programme & $(+)$ & & & $(+)$ & $(+)$ \\
\hline Oslo & & & & & + \\
\hline Australian & $(+)$ & & & & + \\
\hline $\begin{array}{l}\text { Multiple risk factor interventions trial } \\
\text { European }\end{array}$ & & + & $(+)$ & & \\
\hline $\begin{array}{l}\text { International prospective primary prevention study } \\
\text { MRC }\end{array}$ & & & & & + \\
\hline
\end{tabular}

$+=$ Effect significant, $\mathrm{p}<0.05$. 


\section{GUIDELINES FOR CLINICAL PRACTICE BASED ON TRIAL RESULTS}

The major clinical trials discussed in this review have not covered all the problems and possibilities of hypotensive treatment. Their results - though not those obtained by analysis of subgroups of patients defined after the trial was completed-must be used as guidelines for clinical practice. Bearing in mind the limitations of the trials, and also other published work, we suggest the following six guidelines.

Firstly, patients with malignant (accelerated) hypertension need treatment, but for the vast majority of patients who have nonmalignant hypertension there is no "cut off" pressure above which treatment is mandatory. Adequate clinical trials have not been conducted in patients with diastolic pressures greater than $115 \mathrm{~mm} \mathrm{Hg}$, but such evidence as there is suggests that treatment is necessary when the diastolic pressure exceeds $115-120 \mathrm{~mm} \mathrm{Hg}$. There will be no appreciable benefit to an individual patient from treating a diastolic pressure of less than $100 \mathrm{mg} \mathrm{Hg}$.

Secondly, there is no evidence that any particular level of systolic pressure should be treated, and thus there is no reason to treat patients with isolated systolic hypertension, however that might be defined.

Thirdly, blood pressure varies, and in an appreciable proportion of patients with diastolic pressures up to $115 \mathrm{~mm} \mathrm{Hg}$ these will revert to normal values over a few months. It is prudent to check the blood pressure on several occasions before deciding whether to treat and also to measure it yearly in any patient found at any time to have a diastolic pressure greater than $100-105 \mathrm{~mm} \mathrm{Hg}$.

Fourthly, it is probably more important to stop a patient smoking than to treat his mildly raised blood pressure. Any pharmacological treatment causes side effects, so non-pharmacological methods should always be considered; thus weight control is essential as it may be sufficient to control raised pressure.

Fifthly there is no evidence that a different treatment policy is needed in any particular race, sex, or age group, although the effects of different treatments in very elderly patients have not been adequately studied.

Finally, there is no evidence that any particular form of drug treatment is superior to any other, except for a suggestion that $\beta$ blockers are less effective in preventing the complications of high blood pressure in smokers. The choice of initial treatment therefore depends mainly on the expected side effects, which dictate patient compliance, and on cost. On all counts, initial drug treatment should be bendrofluazide. A dose of $2.5 \mathrm{mg}$ daily is as effective as higher doses and although this low dose has not been tested in a large scale trial designed to evaluate its effect on mortality, it would seem logical not to use the higher doses, which probably carry a higher risk of unwanted effects.

\section{References}

1 Kannel WB, Dawber TR. Hypertension as an ingredient of a cardiovascular risk profile. $\mathrm{Br} \mathcal{F} \mathrm{Hosp}$ Med 1974;2:508-24.

2 Kannel WB, Dawber TR, McGee DL. Perspectives on systolic hypertension. The Framingham study. Circulation 1980;61:1179-82.

3 Fisher CM. The ascendancy of diastolic blood pressure over systolic. Lancet 1985;ii:1349-50.

4 Anonymous. Antihypertensive drugs, plasma lipids, and coronary disease [Editorial]. Lance 1980;ii:19-20.

5 Ames RP, Hill P. Antihypertensive therapy and the risk of coronary heart disease. $\mathcal{f}$ Cardiovas Pharmacol 1982;4(suppl 2):S206-12.

6 Anonymous. Lowering blood pressure without drugs [Editorial]. Lancet 1980;ii:459-61.

Andrews G, MacMahon SW, Austin A, Byrne DG. Hypertension: comparison of drug and non drug treatments. Br Med f 1982;284: 1523-6.

8 Veterans Administration Co-operative Study Group. Effects of treatment on morbidity in hypertension. Results in patients with diastolic blood pressures averaging 115 through 129 $\mathrm{mm} \mathrm{Hg.} \mathrm{FAMA} \mathrm{1967;202:1028-34.}$

9 Veterans Administration Co-operative Study Group. Effects of treatment on morbidity in hypertension. II. Results in patients with diastolic blood pressure averaging 90 through 114 $\mathrm{mm} \mathrm{Hg.} \mathrm{F.A.MA} \mathrm{1970;213:1143-52.}$

10 Berglund G, W'ilhelmsen L, Sannersted R, et al. Coronary heart disease after treatment of hypertension. Lance 1978:i:1-5.

11 Hypertension Detection and Follow-up Program Co-operative Group. Five-year findings of the hvpertension detection and follow-up program. I. Reduction in mortality of persons with high hypertension detection and follow-up program. 1. Reductian in mortaly or

12 Hypertension Detection and Follow-up Program Co-operative Group. Five-year findings of the hypertension detection and follow-up program. III. Reduction in stroke incidence among persons with high blood pressure. FAMA 1982;247:633-8.

13 Helgeland $A$. Treatment of mild hypertension: a five year controlled drug trial. The Oslo study Am F . Med 1980;69:725-32.

4 Australian National Blood Pressure Study Management Committee. The Australian therapeutic trial in mild hypertension. Lancet $1980 ; 1: 1261-7$.

15 Australian National Blood Pressure Study Management Committee. Prognostic factors in the treatment of mild hypertension. Circulation 1984;69:668-76.

16 Multiple Risk Factor Intervention Trial Research Group. Multiple risk factors intervention trial Risk factor changes and mortality results. FAMA 1982:248:1465-77.

17 European Working Partv on High Blood Pressure in the Elderlv. Mortality and morbidity results from the European working party on high blood pressure in the elderly trial. Lance $1985 ; 1: 1349-54$.

18 IPPPSH Collaborative Group. Cardiovascular risk and risk factors in a randomised trial of treatment based on the beta-blocker oxprenolol: the international prospective primary presention 1985;3:379-92.

19 Medical Research Council Working Party. MRC trial of treatment of mild hypertension: principal results. Br.Med 7 1985:291:97-104

$20 \mathrm{Hampton} J \mathrm{R}$. Presentation and analysis of the results of clinical trials in cardiovascular disease. Br.Med f 1981:282:1371-3.

21 Sprackling ME, Mitchell JRA, Short AH, Watt G. Blood pressure reduction in the elderly a randomised controlled trial of methyldopa. Br.Med $\mathcal{F} 1981 ; 283: 1151-3$.

Accepted 22 Mav 1986
A 3 year old boy has been diagnosed as having hypertrophic muscular dystrophy. There is no family history and his maternal uncle is not afflicted. The mother's creatine phosphokinase is normal as is that of her sister. When the sister marries is there any possibility of her sons being afflicted?

Between a half and two thirds of mothers of boys with hypertrophic (Duchenne) muscular dystrophy are carriers. Unfortunately, neither a normal creatinine phosphokinase in the mother nor in her sister excludes the carrier status. Three normal creatinine phosphokinases might, however, reduce the probability, and most genetic centres have a curve constructed from obligate carriers and a control population from which probabilities may be calculated. In addition an assessment of the pedigree, especially looking at the number of normal brothers and sons, will also help to alter the probability of being a carrier. Finally, new DNA probes are proving extremely useful in detecting carriers and a combined assessment using all three methods should be attempted at an appropriate genetic centre.- $M$ BARAITSER, consultant in clinical genetics, London.

What drugs and physical measures enhance the resolution of post-traumatic myositis ossificans?

Regrettably there are no really effective measures known which will accomplish this. Traumatic myositis ossificans may follow rupture or bruising of, or frank haemorrhage into, muscle, or follow repetitive minor trauma, for example, in athletes. A similar clinical picture of ossification of muscle, and hence loss of mobility, may also occur in association with paraplegia. ${ }^{1}$ The only measure advocated recently is the diphosphonate etidronate, but results have been disappointing. Strenuous mobilising activity should be avoided lest more trauma, and hence more ossification, results. Large plaques of ossified tissue may be surgically removed when the condition is considered to be stable and not progressing, but the resultant surgical trauma may lead to further ossification. Irradiation has also been suggested in the early stages of the development of the myositis ossificans with unproved results. - C G BARNES, consultant rheumatologist, London.

1 Foster JB. Myositis ossificans. In: Walton J, ed. Disorders of voluntary muscle. 4th ed. Edinburgh: Churchill Livingstone, 1981:817-8.

\section{Correction}

Child sex rings

In the table of this paper by Wild and Wynne (19 July, p 184) the numbers of boys in rings 9,10 , and 11 have moved to the left. The table should read:

\begin{tabular}{cccc} 
& \multicolumn{3}{c}{ Independent rings } \\
\cline { 2 - 4 } Boys & 9 & 10 & 11 \\
\hline & $?$ & 0 & 4
\end{tabular}

We apologise for this error. 